\title{
ATUAÇÃO TEÓRICO-CRÍTICA DO PROFESSOR NAS AULAS DE EDUCAÇÃO FÍSICA NA ESCOLA DE EDUCAÇÃO INFANTIL
}

\author{
Jose Ricardo Silva \\ Faculdade de Ciências e Tecnologias, UNESP, Presidente Prudente, São Paulo, Brasil \\ Irineu Aliprando Tuim Viotto Filho \\ Faculdade de Ciências e Tecnologias, UNESP, Presidente Prudente, São Paulo, Brasil
}

\begin{abstract}
Resumo
O objetivo é apresentar orientações prático-teóricas de natureza crítica, com a finalidade de engendrar possibilidades de atuação para o professor na educação infantil, valorizando a brincadeira nas aulas de Educação Física no desenvolvimento motor e psicológicos da criança. A metodologia, pesquisa-intervenção, pautou-se em observações sistemáticas com posterior intervenção junto às crianças. Identificamos nas práticas da professora influências e tendências não críticas. Posteriormente, iniciamos intervenções de natureza crítica, enfatizando a brincadeira e a ação do professor. Os resultados apontam a importância da mediação do professor nas aulas de Educação Física na educação infantil que suplante o mero desenvolvimento motor para chegar às funções psicológicas superiores.

Palavras-chave: Educação Infantil. Educação Física. Teoria Histórico-cultural.

\section{THEORETICAL-CRITICAL ACTIVITY OF THE TEACHER IN THE CLASS OF} PHYSICAL EDUCATION IN THE SCHOOL OF CHILDREN EDUCATION
\end{abstract}

\begin{abstract}
The objective is to present practical and theoretical orientations of a critical nature, with the purpose of generating possibilities of action for the teacher in the children's education, valuing the joke in the classes of physical education in the motor and psychological development of the child. The methodology, intervention research, was based on systematic observations with subsequent intervention with the children. We identify in the teacher's practices influences and non-critical tendencies. Subsequently, we initiated interventions of a critical nature, emphasizing the play and the action of the teacher. The results point to the importance of teacher mediation in physical education classes in early childhood education that supplants mere motor development to reach higher psychological functions.
\end{abstract}

Keywords: Early childhood education. Physical Education. Historical-cultural theory

\section{ACTIVIDAD TEÓRICO-CRÍTICA DEL PROFESOR EN LA CLASE DE EDUCA- CIÓN FÍSICA EN LA ESCUELA DE EDUCACIÓN INFANTIL}

\section{Resumen}

El objetivo es presentar orientaciones práctico-teóricas de naturaleza crítica, con la finalidad de engendrar posibilidades de actuación para el profesor en la educación infantil, valorizando la broma en las clases de educación física en el desarrollo motor y psicológico del niño. La metodología, investigación-intervención, se basó en observaciones sistemáticas con posterior intervención junto a los niños. Identificamos en las prácticas de la profesora influencias y ten- 
dencias no críticas. Posteriormente, iniciamos intervenciones de naturaleza crítica, enfatizando la broma y la acción del profesor. Los resultados apuntan la importancia de la mediación del profesor en las clases de educación física en la educación infantil que suplanta el mero desarrollo motor para llegar a las funciones psicológicas superiores.

Palavras clave: Educación infantil. Educación Física. Teoría histórico-cultural.

\section{Introdução}

Este artigo foi construído a partir de observação sistemática e intervenção planejada em uma escola de educação infantil, com a finalidade de engendrar reflexões sobre o processo de aprendizagem e desenvolvimento da criança nas aulas de Educação Física. Tais intervenções foram respaldadas numa perspectiva crítica de educação e de Educação Física, com o intuito de construir práticas, devidamente orientadas pelo professor, considerando a brincadeira como caminho para o processo de aprendizagem e desenvolvimento infantil.

Ao apresentarmos orientações prático-teóricas de natureza crítica, construídas a partir da brincadeira, temos o objetivo de engendrar novas possibilidades de atuação para o professor na escola de educação infantil. Enfatizamos as aulas de Educação Física como espaço educativo que deve atender tanto os aspectos motores, como também os aspectos psicológicos do processo de desenvolvimento humano.

Nesse sentido, defendemos o protagonismo do professor como sujeito organizador e orientador de ações prático-teóricas na educação infantil, permeadas por atividades lúdicas com objetos culturais, portanto, mediador no processo de construção de características objetivas (físico-motoras) e subjetivas (psicológicas) das crianças na escola, reconhecendo a brincadeira como atividade principal da criança na infância (LEONTIEV, 1978).

O processo que possibilitou as reflexões que ora apresentamos foi construído a partir de observações sistemáticas, como também considerando as peculiaridades de uma intervenção de natureza crítica realizada em uma escola de educação infantil de uma cidade do interior do oeste paulista. O objetivo desse movimento de observação e intervenção na escola procurou criar condições para pensarmos e estruturarmos processos educativos diferenciados para a Educação Física infantil, enfatizando o papel do professor nesse processo.

Podemos afirmar que a compreensão da Educação Física na educação infantil numa perspectiva crítica torna-se necessária e urgente, sobretudo porque a educação infantil deve assumir o seu compromisso com a educação das crianças, desde a mais tenra idade, superando o modelo assistencialista que predominou na área durante longos anos. É nessa direção que construímos este artigo, procurando situar o lugar da Educação Física na educação infantil e, sobretudo, o papel do professor ao trabalhar com a brincadeira, objeto cultural rico em possibilidades educativas, na escola.

\section{Reflexões histórico-culturais para a atuação do professor na educação infantil}

Pensar possibilidades críticas para a atuação do professor implica que o conceito de crítica ancora-se nos pressupostos da teoria marxiana que enfatizam o processo dialético na compreensão dos fenômenos naturais, humanos e sociais, sejam eles de natureza material ou imaterial, com a finalidade de compreendê-los desde os seus elementos empíricos e observáveis até atingir seus elementos essenciais e não observáveis, na busca de uma compreensão concreta porque multideterminada dos fenômenos presentes na realidade (KOSIK, 2002).

Compreender os fenômenos implica atingir a sua essência, ou seja, a sua concreticidade, pois como afirma Kosik (2002, p. 15) "sob o mundo da aparência se desvenda o mundo real" e para isso se faz necessária a ação humana, mas não uma ação pragmática, utilitária e 
empirista, mas, sim, uma ação crítica e reflexiva, pensada e planejada com finalidade de transformar a realidade.

O desenvolvimento de uma prática profissional efetivamente crítica na Educação Física infantil deve ser capaz de construir-se dialeticamente, no sentido de compreender as contradições postas na educação e na escola, assim como compreender a natureza e a especificidade do ser humano, especialmente as crianças, dada a sua situação social de desenvolvimento na escola. Nesse sentido, a prática do professor precisa efetivar-se como práxis (VÁZQUEZ, 1969).

Defendemos que a Educação Física infantil, para superar o pragmatismo e o espontaneísmo, precisa conceber suas ações como críticas, as quais devem estruturar-se, principalmente, a partir da brincadeira e de outras atividades lúdicas coletivas, voltadas a vivências de natureza crítica e consciente, devidamente orientadas pelo professor na escola.

Outra questão preponderante e necessária é que a Educação Física infantil precisa assumir o compromisso político com a melhoria da escola pública e com o desenvolvimento das crianças que lá se encontram, na defesa constante de melhores condições de aprendizagem e desenvolvimento desses sujeitos. Considerando que na escola pública encontram-se as crianças oriundas da classe trabalhadora e, por isso, necessitam de condições diferenciadas de formação humana.

Leontiev (1978) enfatiza que o movimento da história e o processo de desenvolvimento humano são possíveis a partir da efetiva transmissão às novas gerações dos objetos culturais construídos pela humanidade. Isso implica um processo educativo comprometido com a socialização dos objetos culturais e, no contexto deste estudo, enfatizamos a brincadeira como uma possibilidade cultural fundamental no processo de formação das crianças na escola, na direção da sua humanização.

Para a efetivação desse processo, a criança na escola precisa da mediação de outro ser humano e, nesse sentido, o professor torna-se sujeito imprescindível. É o professor quem criará as condições de aprendizagem e desenvolvimento para as crianças a partir do objeto cultural brincadeira e, ao mesmo tempo, possibilitará acesso e apropriação de brinquedos e outros objetos culturais adequados às crianças da educação infantil, com vistas ao seu processo de humanização.

Para Marx (2004), a essência humana encontra-se no intercâmbio entre o homem e a natureza, sendo que, para realizar-se como ser humano e humanizar-se, essa atividade precisa constituir-se como vital ou humanizadora, ou seja, precisa realizar o ser humano e potencializar as suas capacidades e habilidades de forma a realizá-lo como sujeito de seu processo de aprendizagem e desenvolvimento.

Para Oliveira (2006, p. 7), o trabalho constitui-se como um processo em que o homem se apropria da matéria natural e de forma a utilizá-lo para a sua própria vida, tornando os objetos que foram apropriados verdadeiros "órgãos da sua individualidade". Ou seja, a partir da atividade vital, cada ser humano toma para si os bens da natureza e os bens elaborados pelo homem a partir da transformação da natureza, ou seja, os bens culturais, convertendo-os em características, possibilidades e potencialidades da sua individualidade.

É nesse processo dinâmico de ação consciente e intencional na escola que o professor, ao realizar atividades educativas em direção à apropriação dos objetos da cultura através da Educação Física, engendra condições dialéticas de hominização e humanização (LEONTIEV, 1978), tomando a brincadeira como objeto essencial da cultura corporal para sua ação práticoteórica e voltada ao desenvolvimento omnilateral, ou seja, tanto para o desenvolvimento motor como também para o desenvolvimento psicológico das crianças.

Para Leontiev (1978), ao apropriar-se dos objetos da cultura, pela atividade social, os seres humanos apropriam-se, simultaneamente, das operações motoras incorporadas nos respectivos objetos, sendo que esse processo efetiva-se como uma reorganização dos movimen- 
tos naturais e engendra a formação de faculdades motoras superiores. Para o autor, a apropriação do objeto cultural consiste, portanto, na apropriação "das operações motoras que nele estão incorporadas. É ao mesmo tempo um processo de formação ativa de aptidões novas, de funções superiores 'psicomotoras', que 'hominizam' a sua esfera motriz" (LEONTIEV, 1978, p.269).

Nesse movimento de construção, hominização e humanização das crianças na educação infantil, pela via da ação com os objetos culturais nas relações sociais permeadas pela brincadeira, cada indivíduo, ao realizar uma atividade devidamente orientada pelo professor, pré-idealiza, representa mentalmente, se comunica através de linguagem oral e corporal e, nesse processo educativo intencional, desenvolve novas faculdades motoras e funções psicológicas superiores, sempre em função de motivos sociais e da vida em sociedade.

$\mathrm{Na}$ Educação Física infantil, essa atividade educativa crítica passa a ganhar importância, mediante o processo de superação das características pragmáticas e espontaneístas presentes na área. Nessa direção, o professor precisa criar condições adequadas para a apropriação de objetos culturais fundamentais para as crianças aprenderem e se desenvolverem na escola e de acordo com a sua situação social de desenvolvimento (VIGOTSKI, 2006).

Reiteramos que, a partir da efetivação de um trabalho de natureza crítica na Educação Física, o professor na educação infantil terá condições de viabilizar processos de desenvolvimento ominilateral das crianças. Isso porque a especificidade prático-teórica dessa disciplina garante aprendizagem e desenvolvimento de aspectos motores, psíquicos e sociais dos indivíduos.

Na superação dessa dicotomia, há que prevalecer a dialética entre ato motor e ato psíquico, como apregoa a teoria histórico-cultural. Logo, a prática da Educação Física infantil, numa perspectiva crítica, deve reconhecer as crianças na sua totalidade em processo de aprendizagem e desenvolvimento, tendo o professor como sujeito fundamental desse processo.

É nesse sentido que o professor deve situar-se no movimento consciente e intencional de transformação do humano na escola. Para o esclarecimento dessa questão, nos remetemos a Saviani (2000, p.11), quando afirma que o desenvolvimento humano não é natural, ou seja, o homem "não nasce sabendo ser homem, vale dizer, não nasce sabendo sentir, pensar, avaliar, agir. Para saber pensar e sentir; para saber querer, agir ou avaliar é preciso aprender, o que implica o trabalho educativo".

\section{Investigando a realidade na escola: metodologia de pesquisa e resultados}

A pesquisa-intervenção que ora apresentamos ocorreu em uma instituição de educação infantil, mais especificamente na pré-escola, de uma cidade do interior do estado de São Paulo, e foi realizada com um agrupamento de crianças com idade entre 4 e 5 anos, atendidas por uma professora polivalente. Os dados foram coletados semanalmente a partir de observações feitas in loco ao longo de três meses, nos momentos especificados na rotina institucional como aulas de Educação Física. Durante as observações, para constatar elementos da prática educativa, realizamos registros escritos.

A observação, segundo Lüdke e André (1986), é uma técnica investigativa que permite ao pesquisador o contato direto e próximo com o objeto pesquisado. Utilizando essa técnica investigativa, torna-se possível uma relação mais estreita do pesquisador com a realidade pesquisada, fato que proporciona uma experiência direta com os sujeitos participantes do processo, no caso, a professora e as crianças no interior da escola. As observações foram tabuladas considerando as atividades realizadas pela professora nas aulas de Educação Física e categorizadas como atividades de natureza crítica, relacionadas ao desenvolvimento de funções psicológicas como linguagem, pensamentos, sentimentos e consciência, ou não críticas, se relacionadas ao desenvolvimento motor das crianças. 
Ao longo das observações, notamos que as brincadeiras propostas pela professora nas aulas de Educação Física demonstravam duas tendências, o circuito motor e a brincadeira livre, as quais tomamos como objetos de análise. Portanto, considerando a regularidade dessas atividades propostas pela professora, foi possível identificar sua prática como não crítica.

A constatação de práticas não críticas configurou-se pela realização de circuitos de obstáculos utilizando bambolês enfileirados, túneis de tecido, cordas esticadas, plataformas almofadadas e cones em ziguezague. Cada elemento era posicionado de forma que as crianças realizassem o percurso recorrendo a diferentes habilidades, tais como correr, saltar, engatinhar, pular, arrastar-se para a transposição dos obstáculos, mantendo o foco no desenvolvimento motor dos sujeitos.

Outras práticas pedagógicas foram observadas e, dentre elas, a "brincadeira livre". A professora assegurava às crianças tempo, local e brinquedos para que elas criassem suas brincadeiras, individual ou coletivamente. Nesses momentos, a professora apenas observava as crianças e, eventualmente, mediava os conflitos, sem fazer qualquer discussão acerca do conteúdo e da forma das brincadeiras das crianças.

De forma consciente ou não, os momentos destinados às aulas de Educação Física que observamos apresentaram características que favorecem a sua identificação a concepções teóricas, influências e tendências práticas que consideramos não críticas, dado o seu teor pragmático e espontaneísta e voltado exclusivamente para os aspectos do desenvolvimento motor das crianças.

De modo geral, as atividades realizadas em aula pela professora apresentaram características da psicomotricidade, dos jogos recreativos e do laissez-faire. Nossas observações revelaram elementos fundamentais da abordagem da psicomotricidade francesa na Educação Física, pautada pela repetição de movimentos (andar, saltar, correr e pular), assim como pela demonstração de elementos psicomotores, tais como equilíbrio, coordenação final e global, orientação espaço-tempo, lateralidade e esquema corporal, atividades relacionadas à "hora do desenvolvimento psicomotor", conforme orientações apregoadas por Le Boulch (1982), atividades essas restritas a esses aspectos do desenvolvimento humano e sem qualquer elemento que não seja relacionado ao corpo e aos movimentos da criança.

Ainda sobre as práticas observadas, as análises nos remeteram ao texto $O$ brincar (BRASIL, 1998), versão preliminar do Referencial Curricular Nacional para a Educação Infantil (RCNEI). O texto elenca tendências pedagógicas presentes em creches e pré-escolas quanto ao brincar, denominadas como atividade recreativa e laissez-faire, situação identificada quando a professora permite que as crianças se organizem de forma independente para a realização de brincadeiras livres, sem sequer preocupar-se com os conteúdos das brincadeiras.

A tendência recreativa está ligada aos momentos em que a brincadeira é concebida como atividade que permite relaxamento e desgaste de energias, realizada após as atividades "sérias" das disciplinas regulares. O laissez-faire refere-se à prática espontânea da criança. Em ambas as tendências, a atuação do professor é somente acompanhar as crianças, deixandoas à sua própria espontaneidade, evitando proibições e tampouco interferências no brincar dos sujeitos (BRASIL, 1998).

Posteriormente a esse período observacional, realizamos intervenções prático-teóricas a partir de uma concepção crítica de Educação Física permeada pela teoria histórico-cultural junto às crianças da escola. Segundo Moreira (2008, p.430), "a pesquisa-intervenção tem contribuído para o rompimento da dicotomia que separa 'sujeitos' de 'objetos' de pesquisa" e, nesse sentido, defendemos que é no encontro entre pesquisadores e sujeitos, em ação material e concreta, que torna-se possível construir em cada indivíduo singular e sujeito do processo de pesquisa a humanidade construída histórica e coletivamente pelo conjunto dos homens (SAVIANI, 2000). 
A teoria histórico-cultural nos orienta a defender a brincadeira de papéis sociais como a atividade guia do processo de desenvolvimento infantil na pré-escola. Segundo Leontiev (1978, p.65), a atividade guia não é aquela que a criança realiza com maior frequência, mas sim a atividade "[...] cujo desenvolvimento governa as mudanças mais importantes nos processos psíquicos e nos traços psicológicos da personalidade da criança, em um certo estágio de seu desenvolvimento".

Ao assumir papéis, a criança coloca a si mesma no lugar do outro. Ela faz isso utilizando-se de objetos, funções, profissões, atos rotineiros e dá vida ao que pôde captar mentalmente. Ainda, durante as brincadeiras, a criança aprende a colaborar, leva em consideração as opiniões e os interesses alheios, pois encontra no grupo as condições para o desenrolar da brincadeira. Sob esse enfoque, a brincadeira favorece o desenvolvimento cultural, já que é por meio dela que a criança se apropriará das objetivações humanas (NUNES; VIOTTO FILHO, 2016).

A partir dessas orientações é que lançamos mão das brincadeiras para que as crianças vivenciassem experiências humanas, sociais e históricas nos momentos da rotina destinados à Educação Física. Dessa forma, enfatizamos não apenas os atos motores, mas também as funções psicológicas na busca do desenvolvimento omnilateral dos sujeitos. Foram realizados 12 encontros de intervenção com as crianças, no interior da própria escola, nos horários destinados à Educação Física. Os encontros tiveram duração de 50 minutos e contaram com a participação da professora da escola.

Iniciamos nossas intervenções levando em consideração as brincadeiras que as crianças criaram nos momentos em que a professora as deixou livres. Quando brincam, as crianças externalizam sua compreensão de mundo - falas, comportamentos, respeito aos papéis e às regras sociais, etc. Essas brincadeiras são momentos que precisam ser captados pelo professor a fim de conhecer o modo como as crianças compreendem o mundo dos adultos (SILVA; MELLO, 2015) e, dessa forma, intervir de maneira consciente.

Observamos o quanto as crianças reproduzem elementos do cotidiano. Assumem papéis sociais vivenciados, sejam pontos positivos e negativos dessas situações sociais. Contudo, a relação entre as crianças durante as brincadeiras não pode ficar no âmbito da observação de suas falas e comportamentos e, ao participar ou intervir na brincadeira, cabe ao professor contribuir com esse processo histórico e social que é o brincar coletivo.

Em situações como brincar de motorista, polícia e ladrão, brincar de professor ou diretor de escola, conforme propomos, configura-se oportunidade única para que o pesquisador possa intervir no processo, de modo a contribuir para uma compreensão diferenciada e crítica por parte das crianças sobre tais papéis sociais. Nunes e Viotto Filho (2016) salientam que a atividade do brincar na escola deve ser orientada pelo professor no sentido de não permitir que as crianças reproduzam estigmas, preconceitos e discriminações próprias da sociedade capitalista.

Os autores defendem a orientação das crianças na sua forma de falar, pensar, sentir e agir, durante a brincadeira, para que tenham oportunidades educativas diferenciadas e tornemse mais conscientes e críticas acerca dos papéis sociais assumidos na atividade do brincar (NUNES; VIOTTO FILHO, 2016). Considerando a importância da brincadeira na vida das crianças, podemos afirmar que é nesse movimento de apropriação e objetivação da cultura humana que cada criança se desenvolve de forma omnilateral. Nesse processo, encontra as condições de humanização, pois constrói, na relação com as outras crianças e com o professor, suas funções psicológicas superiores como linguagem, pensamentos, sentimentos e consciência, bases fundamentais para a construção de sua personalidade.

Durante o processo de intervenção realizado na escola, fizemos perguntas que nos ajudaram a compreender o contexto em que as crianças estavam inseridas para, em seguida, propor variações nas atividades, para que a brincadeira avançasse em relação ao cotidiano e à 
mera reprodução dos papéis da sociedade, no sentido de proporcionarmos brincadeiras repletas de diálogos e reflexões sobre a realidade representada em cada uma das atividades realizadas nas aulas de Educação Física.

Outro exemplo de intervenção na brincadeira ocorreu quando as crianças estavam brincando de "pirata" na caixa de areia e não sabiam o nome de todos os elementos presentes no navio pirata, tais como luneta, manche, vela, proa e popa. Na intervenção, nomeamos "luneta" aquele objeto utilizado para o pirata enxergar algo à longa distância, assim como "leme" o para pilotar o navio e também indicamos a "proa" e a "popa". De imediato, as crianças compreenderam esses conceitos e reorganizaram a direção e o modo de conduzir a embarcação.

Defendemos que cabe ao professor propor e elucidar temas, conteúdos e conceitos a serem compreendidos e internalizados pelas crianças, os quais serão objeto de externalização para as suas ações nas brincadeiras. A forma de expressão desses elementos pelas crianças denota o nível de compreensão dos significados das palavras, conteúdos e conceitos abordados durante a brincadeira, como, também, oferecem indícios e nos remetem ao nível de desenvolvimento real e às possibilidades concretas de aprendizagem e desenvolvimento das crianças na escola.

Nessa perspectiva, afirma Marino Filho (2012, p.161), torna-se imprescindível no fazer pedagógico "[...] conhecer esses conteúdos, os seus signos e a significação que a criança atribui aos objetos e situações, para que possamos estabelecer uma relação de coordenação do processo de ensino [...]". Decorrente dessa afirmação do autor, podemos pensar que, numa próxima vez, quando as crianças brincarem de "navio pirata no banco de areia", os elementos apresentados a elas poderão compor a organização do cenário e dos diálogos.

Assim, os profissionais da educação intervêm nas brincadeiras das crianças - em momento adequado - com o objetivo de ampliar a compreensão de mundo das crianças e, a partir dessa troca, planejar as próximas atividades para promover o desenvolvimento infantil (SILVA; MELLO, 2015). Agindo dessa forma, o professor estará levando a criança a progredir de seu nível de desenvolvimento real, aquele em que ela se encontra, para um nível de desenvolvimento mais avançado, como afirma Vigotsky (2006).

Ainda, para que os temas e conteúdos das brincadeiras das crianças sejam ampliados, é preciso que os professores proporcionem novas experiências de conhecimento das relações sociais e da diversidade própria da atividade humana na sociedade. Experiências tais como visitas a museus, fábricas, lojas, comunidades indígenas, zoológicos, praças e patrimônios públicos, teatros, galerias de arte, enfim, são importantes, pois são espaços e situações que permitam perceber as diferentes formas de organização da atividade humana. Tais visitas, sempre seguidas de discussões coletivas, possibilitam às crianças compreender o desenvolvimento dos papéis e a atenção a novos temas da atividade humana (SILVA; MELLO, 2015), fatores que contribuem para o seu processo de conscientização e humanização.

É importante salientar que brincar de casinha, polícia e ladrão, super-herói revela, por vezes, manifestações de preconceito, segregação, discriminação e até mesmo de violência. Nessa situação, valores e atitudes expressos na brincadeira devem ser comentados, discutidos e problematizados, sendo que as manifestações captadas pelo professor atento e preocupado em promover o desenvolvimento infantil podem orientar suas intervenções, de modo a transformar compreensões equivocadas das crianças.

Falas como "isso é de menino/menina", "essa brincadeira é de menino/menina", "azul é de menino, rosa é de menina", "menino não lava a louça", "menina não joga bola" foram recorrentes nas intervenções de jogos de papéis que propomos nos encontros de intervenção. Vimos que, muitas vezes, as próprias meninas incorporavam a fala dos meninos e deixavam de participar daquelas atividades rotuladas como masculinas. Na busca da superação de manifestações de alienação durante as brincadeiras, conforme apontaram Nunes e Viotto Filho 
(2016), as intervenções de natureza crítica devem caracterizar-se, sobretudo, pela realização de brincadeiras cooperativas e coletivas, sempre permeadas pela orientação do professor e pelo diálogo das crianças, tematizando questões do cotidiano, sem, no entanto, permitir que as crianças reproduzam ações violentas, preconceituosas e discriminatórias, dentre outras.

É interessante perceber que no decorrer de um processo de intervenção de natureza crítica e marcado pela atuação consciente do professor, ainda que com muitas dificuldades, pois a alienação social se faz presente na escola, a possibilidade de construção de novas relações sociais através da brincadeira é real e essa possibilidade depende da atuação do professor. Esse fato é constado quando identificamos no decorrer do processo de intervenção situações que denotam uma convivência social diferenciada entre as crianças e que passa a ser permeada pelo diálogo, pelo respeito e pela compreensão do outro, como verificamos. Tais situações humanizadoras demonstram caminhos para a superação da alienação cotidiana notoriamente reproduzida no preconceito, na discriminação e na violência presente na sociedade.

Podemos afirmar, considerando os dados das observações, assim como diante dos dados coletados no processo de intervenção, que as possibilidades de transformação humana existem e são reais e que o trabalho educativo crítico do professor torna-se imprescindível. $\mathrm{Na}$ Educação Física infantil, torna-se possível, pelo trabalho do professor, a construção de condições diferenciadas tanto para o desenvolvimento motor quanto para o desenvolvimento psíquico das crianças, enfatizando a brincadeira como objeto cultural essencial da cultura corporal e necessário para o desenvolvimento multilateral das crianças na escola de educação infantil.

\section{Considerações finais}

Procuramos apresentar e discutir neste artigo os princípios teóricos e alguns resultados de um processo de pesquisa-intervenção realizado no interior de uma escola de educação infantil e no contato com professora e crianças de uma sala de aula, enfatizando a brincadeira como objeto fundamental das aulas de Educação Física e o professor como sujeito imprescindível na efetivação dessa atividade junto às crianças.

As observações sistemáticas realizadas na escola revelaram tendências não críticas presentes nas práticas pedagógicas dos professores, dado o seu teor pragmático e espontaneísta e voltado exclusivamente para os aspectos do desenvolvimento motor das crianças. Entendemos que essas tendências não críticas pouco contribuem para o desenvolvimento multilateral das crianças na escola.

A partir das observações realizadas, planejamos um processo de intervenção de natureza crítica que foi realizado com crianças de uma sala de aula da escola e pautamos nossas práticas pedagógicas considerando os pressupostos da teoria histórico-cultural, enfatizando a brincadeira como atividade guia do desenvolvimento infantil, sobretudo durante as aulas de Educação Física na escola de educação infantil.

Nesse sentido, enfatizamos a atuação do professor como sujeito essencial na construção de condições diferenciadas de aprendizagem e desenvolvimento, tanto dos atos motores como das funções psicológicas das crianças, na busca de um desenvolvimento multilateral desses sujeitos na escola. No bojo dessa discussão, o professor torna-se imprescindível para a construção de um trabalho educativo crítico e humanizador, responsável pelo desenvolvimento da totalidade humana na escola, superando concepções e práticas reducionistas e positivistas na escola.

Enfatizamos que, no planejamento e construção de um trabalho educativo de natureza crítica, há que se reconhecer tanto os fenômenos sociais e institucionais quanto os fenômenos humanos, numa perspectiva dialética e, portanto, em contínuo e contraditório processo de desenvolvimento histórico-social. Para a efetivação desse processo, o professor na educação 
infantil precisa apropriar-se dessa forma de compreensão da realidade humana e social, a partir dos pressupostos teóricos e metodológicos da teoria histórico-cultural, pois consideramos que esse referencial abarca as multideterminações do processo de formação humana na escola.

É importante salientar que um trabalho educativo, em que o professor assume seu compromisso como agente de transformação dos seres humanos na escola, precisa ser construído e compartilhado com todos os sujeitos participantes da escola, sobretudo os gestores e demais professores, pois trata-se de um projeto coletivo que precisa ser incorporado e assumido pela escola na sua totalidade. Em outras palavras, estamos todos envolvidos na vida uns dos outros na escola e estabelecendo relações sociais recíprocas, as quais, em grande medida, tornam-se conteúdos de nossa existência social.

Temos clareza que vivências de pesquisa-intervenção como esta que sistematizamos neste artigo não possibilitarão, por si só, a transformação das escolas e das crianças da educação infantil. No entanto, também temos clareza que existem caminhos teóricos e metodológicos para pensarmos nas transformações necessárias, em conformidade com as condições objetivas presentes na escola, desde que haja participação dos professores na construção de uma educação crítica e transformadora, ou seja, esse processo não é obra de voluntarismos e precisa ser construído coletivamente na escola.

A construção de um trabalho crítico na educação em geral, e na Educação Física na educação infantil em específico, está diretamente relacionada às condições objetivas encontradas na escola, sendo que essa instituição e o trabalho educativo nela realizado precisam ser compreendidos no bojo das relações reproduzidas na sociedade.

Por fim, as condições de transformação da escola, alunos e professores, como também a própria sociedade, não irá brotar espontaneamente das relações sociais. Para que qualquer processo de transformação aconteça, sobretudo na escola, há que haver organização dos sujeitos dela participantes e, nesse sentido, o professor torna-se imprescindível. Defendemos ainda, dada a especificidade de nossa atuação como pesquisadores, que esse processo de transformação social e humano deve iniciar-se desde a escola de educação infantil.

\section{Referências}

BRASIL. MEC/Secretaria de Educação Fundamental. O brincar - Versão preliminar do Referencial Curricular Nacional para a Educação Infantil. Secretaria da Educação Fundamental. Brasília: MEC/SE, 1998.

KOSIK, K. Dialética do concreto. São Paulo: Paz e Terra, 2002.

LEONTIEV, A. O desenvolvimento do psiquismo. Lisboa: Horizonte, 1978.

LE BOULCH, J. O desenvolvimento psicomotor do nascimento até 6 anos. Porto Alegre: Artes Médicas, 1982.

LÜDKE, M.; ANDRÉ, M. E. D. A. Pesquisa em educação: abordagens qualitativas. São Paulo: EPU, 1986.

MARINO FILHO A. Implicações psicopedagógicas da brincadeira: aprender a fazer, aprender a ser. In: VIOTTO FILHO I. A. T.; PONCE R. de F. Psicologia e educação: perspectivas críticas para a ação psicopedagógica. Birigui, SP: Ed. Boreal, 2012.

MARX, K. Manuscritos econômico-filosóficos. São Paulo: Boitempo, 2004. 
MOREIRA, M. I. C. Pesquisa-intervenção: especificidades e aspectos da interação entre pesquisadores e sujeitos de pesquisa. In: CASTRO, L. R. de; BESSET, V. L. (Orgs.). Pesquisaintervenção na infância e juventude. Rio de Janeiro: Nau, 2008. p. 409-432.

NUNES, R.L.; VIOTTO FILHO, I.A.T. A atividade do jogo e suas implicações para o desenvolvimento da consciência da criança na escola. Curitiba: CRV, 2016. v. 1. 126p.

OLIVEIRA, B. Fundamentos filosóficos marxistas da obra vigotskiana. In: MENDONÇA, S. G. L.; MILLER, S. (Orgs.). Vigotski e a escola atual. Araraquara, SP: J.M., 2006.

O trabalho educativo. Campinas: Autores Associados, 1996.

SAVIANI, D. Pedagogia histórico-crítica: primeiras aproximações. Campinas: Autores Associados, 2000.

SILVA J. R.; MELLO S. A. A brincadeira livre como atividade humanizadora na educação infantil. In: VIOTO FILHO I. A. T.; RODRIGUES S. A. Educação e formação humana: interlocuções críticas e dialéticas. Curitiba: Ed. CRV, 2015.

VÁZQUEZ, A.S. Filosofia da práxis. Rio de Janeiro: Civilização brasileira, 1969.

VIGOTSKI, L. S. A construção do pensamento e da linguagem. São Paulo: Martins Fontes, 2001.

Obras escogidas. 2. ed. Madrid: Machado Libros, 2006. tomo IV.

Recebido em: 08/01/2018

Revisado em: 05/04/2018

Aprovado em: 05/04/2018

Endereço para correspondência:

ricardo.unesp@hotmail.com

Jose Ricardo Silva

Universidade Estadual Paulista "Julio de Mesquita Filho" - UNESP-Presidente Prudente.

Rua Roberto Simonsen, 305

Jardim Esplanada

19060900 - Presidente Prudente, SP - Brasil 